\title{
Professional growth of the teacher in the Russian higher technical school: forms of implementation
}

\author{
L.V. Stepanenko ${ }^{1 *}$, E.A. Davidson ${ }^{2}$, and E.L. Plavskaya ${ }^{3}$ \\ ${ }^{1}$ Novosibirsk State Technical University, Novosibirsk, Russia \\ ${ }^{2}$ Novosibirsk State Technical University, Novosibirsk, Russia \\ ${ }^{3}$ Novosibirsk State Technical University, Novosibirsk, Russia
}

\begin{abstract}
This article describes the main directions of the teacher's activity in a higher technical school, associated with various forms of his selfrealization, namely: in the educational process of a modern type, in research work, accompanied by publication activity.
\end{abstract}

\section{A problem statement}

The Russian higher technical school today is at the epicenter of important and complex economic processes, which are accompanied by the acceleration of the economic development of the Russian state and the implementation of economic breakthroughs in connection with the entry into the era of digitalization. This determines the continuous process of modernization of the Russian higher technical school and the multi-vector activity of the teacher, which is aimed at training new generations of future specialists with professional and general cultural competencies. Today, strict requirements are imposed on the teacher of a higher technical school, in connection with which the main tasks of the teacher's self-realization are: a continuous process of increasing knowledge, skills and abilities in terms of self-education, studying a wide pedagogical experience and extracting positive and negative lessons from the pedagogical practice of the past, deep immersion in the subject area, proficiency in the professional language of the subject and their own distinctive linguistic style, possession of a broad thesaurus and the ability to conduct an emotional presentation of the subject, awakening the axiomatic of interest among students. These aspects are the basis for the mastery and creative content of the teacher's activity.

The ongoing modernization of the Russian higher technical school is accompanied by an update of the regulatory framework, conceptual expansion of modules. In this context, the teacher's activities are related to the deepening of the content of the module (subject field), the search for new methodological and methodical approaches to the organization of the educational process, namely: the effective use of traditional and innovative forms of teaching and upbringing, the development of new digital formats. All of this is aimed at

\footnotetext{
*Corresponding author: ipcs-profped@yandex.ru
} 
creating a professional and general cultural environment for the training of engineering and technical personnel, responding to the social challenges of the time.

Today, the teaching staff is tasked with analyzing current changes, the ability to fit into the context of time and quickly respond to urgent challenges of social reality (including in force majeure situations), mastering new formats and identifying promising trends in the organization of the educational process.

Both social and purely educational processes are associated with the fact that today the teacher must have the qualities of professional flexibility and mobility, responsiveness, orientation in the socio-cultural situation, the ability to make creative and creative decisions and cooperation, the ability to conduct dialogue and show tolerance in certain emotionally tense situations, to be aware of their personal contribution to solving pedagogical problems. That is why Russian higher technical education develops in the wake of maximizing the creative abilities of the teacher, expanding the field of his intellectual activity and personal responsibility for the effectiveness of the activities carried out.

Moreover, the transition of Russian society to the format of the digital economy, actualizes in modern education both educational, scientific and practical orientation. In this regard, socio-cultural adaptability, professional competence, general cultural erudition and competitiveness are seen as the key characteristics of the personal qualities of a teacher in a higher technical school. Therefore, close attention to the teacher's activities, analysis of the vectors of its development, become an important strategic component of the achievements of a particular higher school.

Thus, the relevance of our article is determined by the need to analyze the growth and development opportunities of a teacher in terms of revealing the creative potential of his personality in a modern higher technical school.

\subsection{The objective of the work}

The theoretical and methodological basis of the study is:

- modern methodology of scientific pedagogical and psychological research - A.V. Belotserkovsky [1], E.V. Karavaeva [2], V.V. Kondratyev [3], G.M. Romantsev, N.V. Ronzhina, E.F. Zeer [4], I.Ye. Uflyand, L.V. Zanina, L.V. Goryunova [5] and others, necessary in the study and analysis of the conceptual directions of modernization of the higher technical school, which include "Education", "Science", "University and Society", adaptation of the Russian educational system in the Bologna process. Note that a huge array of modern research is devoted to a very deep and comprehensive analysis of these areas with the identification of positive and negative aspects of their implementation:

- the theory of personality development and motivational activity by A. Maslow [6], V.D. Shadrikov [7] and others, which formed the basis of the idea of growth and development of the subject of the educational process, disclosure of thecreative potential of the individual. Within the framework of this academic problem, the possibility of considering the personality of a teacher from the standpoint of motivation of activity, stimulation to effective pedagogical work, which makes it possible to identify the image characteristics of teachers;

- systems for assessing the rating activity of teachers, presented in the works of E.N. Arkhipova [8], I.E. Zadorozhnyuk, S.V. Kireev [9], I.V. Zakharova [10], V.A. Lazarenko, V.A. Lipatov, T.A. Oleinikova, D.A. Severinova, N.B. Filinova [11], I.G. Manoilenko [12] and others, which are now especially actively analyzed by the pedagogical community;

- a large array of studies is devoted to the actualization of engineering and technical training in connection with the set state tasks, including the work of M.G. Ganchenkova, I.E. Zadorozhnyuk, V.M. Kalashnik [13], V.M. Prikhodko, Z.S. Sazonova [14]. 
Due to the fact that modern researchers are very broadly covering various aspects of pedagogical activity, we will try to dwell in more detail on the characteristics of the conceptual directions of modernization of a higher technical school in terms of the need for the teacher to fulfill the conditions of an effective contract.

\section{Materials and the results of the research}

The above allows us to reveal the contradiction between the need and the search for ways of self-realization of the teacher in a higher technical school, as well as the designation of the possibilities of using the accumulated pedagogical experience in modern practice, on the one hand; the level and degree of preparedness of students, their adaptation to the educational process, on the other. This contradiction has led to the search for theoretical and practical approaches to the organization and development of a higher technical school at the present stage, carried out by the joint activities of the teaching staff.

Proceeding from the contradiction, the problem arose of identifying and using effective methods and forms of teaching and upbringing by the teaching staff in order to maximize the personal potential of students and the formation of their professional and general cultural competencies.

In this regard, the purpose of this article is to analyze the theory and practice of pedagogical activity in a higher technical school, to determine the possibilities of applying the progressive pedagogical experience of the past in modern conditions, to identify promising forms of organizing educational, scientific and practical directions.

Therefore, in this work, we solved the problems associated with the analysis of the process of implementation of the conceptual ideas of the development of a higher technical school by the pedagogical community, the allocation of effective methods and forms of organizing the educational process and the identification of promising directions for the teacher's self-realization.

In our work, we proceeded from the assumption that the pedagogical experience of the development of a higher technical school can be effectively used in modern conditions, if a retrospective analysis is carried out (the theory and practice of past years is subjected to critical reflection), the features of the organization of the educational process are revealed at the present time, forecasting the possibilities of using positive pedagogical experience at the present stage (based on analysis, comprehension and correlation of traditional and innovative formats of building the educational process). These are the components on the basis of which the effectiveness of pedagogical activity is determined today.

The higher technical school today is developing in several main directions, among which we see as relevant "Education", "Science", "University and Society".

Today the pedagogical community is involved in the implementation of one of the conceptual directions - "Education", the key idea of which was the creation of a modernized educational base. The process of updating the Federal State Educational Standard for Higher Education (FSES HE), launched in the 2000s, does not lose its relevance today, when one generation of FSES HE is replaced by another. According to our assumption, the developers of the Federal State Educational Standard of Higher Education are puzzled by the search for the most acceptable model for the presentation of the subject (module) that responds to the social challenges of the information society. In particular: to solve global problems in the economic development of Russia in terms of economic breakthroughs - the introduction of a digital format, and, more broadly, - changes in the situation on the labor market according to monitoring the list of demanded professions [15]. In connection with such positions, formulated at the state level, a priority area in higher education in general is becoming a higher technical school, whose activities are related to the training of engineering and technical personnel, their accumulation within the country, and the 
preservation of intellectual potential aimed at implementing global tasks in the economy. (informatization, digitalization).

In the conceptual design of new generations of the Federal State Educational Standard of Higher Education, didactic tools for constructing modules (subjects or academic disciplines) are presented based on the correlation of goals and objectives, the specifics of content, the correlation of traditional and innovative methods of teaching and upbringing, and, a practice-oriented orientation of the educational process in connection with actualization of one of the conceptual directions of modernization of a higher technical school - "University and Society" [16]. However, we consider it necessary to note that with the advent of each new generation of the Federal State Educational Standard of Higher Education, a tendency to deepen and expand the information field of the module (subject) is clearly revealed. Consequently, the teacher's activity in the implementation of the new educational standard is aimed at the need to form the information capital of the student's personality - the development of professional competencies and the enrichment of his socio-cultural thesaurus.

This intensive pace of renewal of the Federal State Educational Standard of Higher Education puts the teacher in a very strict framework of the need to study, deep understanding of the new educational standard, on the one hand, and constant work on his own conceptual, methodological and methodical base, on the other. Due to the fact that the generational turnover of the Federal State Educational Standard of Higher Education is still taking place, the practicing pedagogical community can only adapt in these difficult conditions, and actively seek the most adequate and constructive forms and methods of training and education. In our opinion, the conceptual expansion of the module occurs in the context of an information attack on both the teacher and the student. In our opinion, the negative aspects of this process of updating the FSES of HE is the danger of very superficial knowledge of students, the impossibility of deep immersion in the subject. Along the way, we note that under these conditions, the teacher's participation as an organizer of the educational process is actualized (due to the fact that not all students are capable of independent activity - self-study, self-discipline, self-control).

In this field of the teacher's activity in the new generation of FSES HE, the key task is to find effective individual approaches to the student (namely, in the ability to work with information - to analyze research, educational and methodical literature, to systematize information material). In particular, our pedagogical practice has developed methodological and methodical components that are implemented by the teacher in interactive teaching and upbringing (on the example of the humanitarian cycle "General history. History of Russia"; "Fundamentals of personal and communicative culture"). These include:

- presentation of historical and cultural material using different methodological approaches - retrospective, ideographic, problem-chronological, comparative, etc.;

- visualization of information (accompanying the stated lecture material with tables comparative-comparative, diachronic for different historical periods, displays of masterpieces of artistic culture, etc.);

- presentation of interactive forms of education and upbringing (different types of dialogue - conversation, discussion, "brainstorming", etc.), aimed at the development of "higher mental functions" of students: development of the speech apparatus; acquisition of skills to work with different types of information carriers - textbook, educational and methodological complex, electronic textbook, tables, Internet resources, periodicals; expanding language capabilities and enriching the thesaurus;

- mastering by students the techniques of constructing a system of arguments through mastering the conceptual apparatus of the subject;

- development of the ability of critical perception of information by students and drawing up structural and logical diagrams when analyzing key problems; 
- independent processing, structuring and forms of information minimization in the form of reference signals;

- compilation by students of their own bank of information in an adapted and readable form.

Consequently, the conditions for fulfilling the federal state educational standard are aimed at constructive organization of the educational process. The teacher is responsible for the presentation of the module, and in the presentation of the content, and in the mastery of the students of the conceptual apparatus, methodology and methods of the studied discipline. In this process, the teacher solves the problems of maximum informational content of the academic discipline, on the one hand, and the quality of mastering the material by the students themselves, on the other.

The educational process is built today on the basis of the attitude to the student's personality as to the subject of education and the mission of the pedagogical community is seen in the most complete disclosure of his creative and creative abilities, in order to form a creatively oriented personality, capable of searching, novelty, non-standard solutions in an independent professional activity.

At the present stage, pedagogical practice offers different forms of education - full-time, part-time and, updated by time in conditions of force majeure, (aggravated social situation), - distance learning.

We will try to analyze the conduct of the educational process in full-time format, taking into account other possible ones introduced in connection with the social challenges of the time.

We can talk about a balanced combination of traditional (lecture, seminar, practical) and innovative (online webinars) forms. And let us only make the assumption that online forms can be introduced as educational and methodological support, complementing the full-time format. Today, due to the circumstances, distance learning is being introduced through various online formats. Among them are online education - webinars, electronic educational and methodological complexes (EEMK) using presentations (the database has been formed since 2013 and almost every teacher is able to create their own EEMK). The teacher is required to respond quickly and master these new formats. Such practice is only entering educational life and presupposes the readiness of the entire pedagogical corps to master them. The degree of effectiveness of distance learning is today a matter of forecasting. In this regard, let us assume that this format can be implemented only in parallel with full-time training, and will be introduced in conditions of force majeure, no more than.

Thus, the face-to-face format offers a variety of teaching methods. However, in the context of our attention, full-time education and upbringing is actualized, based on the development of a reflective dialogue by students - interactive communication between a teacher and a student, the development of hearing and listening skills, promptly reacting to statements, correctly and tolerantly treating another opinion, position, judgment. Consequently, a diversely organized educational process is aimed at the formation of a baggage of knowledge, abilities and skills - what today constitutes the concept of the information capital of an individual and a teacher and a student.

From the standpoint of adaptation of a student in the full-time educational process, analysis of the degree of assimilation of diverse information of educational modules, the adequacy of understanding goal-setting, tasks and the result of educational activities of students, the development of higher mental functions of the student's personality (perception, sensory-emotional sphere, thinking, speech activity, imagination).

We will try to characterize problem areas in their formation among students and possible forms of overcoming.

In the development of the primary function - perception - the key components are seen the ability to read, comprehend information. Then more complex processes of analysis, 
interpretation and translation are included - analytical processing of information. In this context, in the real teaching and educational process, the teacher is faced with certain problems in organizing work on mastering the material for students. We consider it necessary to identify these problems and try to find a mechanism to overcome them. In particular: unpreparedness of the student for the perception of a wide information field; inability to adequately perceive information; ignorance of how to work with information; inability or unwillingness to make an effort on oneself in terms of reading, analysis, comprehension, generalization - the process of self-organization itself; lack of understanding that in the development of information it is necessary to read the relevant research, educational and methodological literature - textbooks, monographs, articles.

Another screaming problem is the limitation of the student's vocabulary and the reluctance, misunderstanding that it is necessary to work with the vocabulary apparatus independently in terms of saturating the language with words (provided that the language is adaptable and open to interlanguage interaction, due to active updating, words penetrate into the native language from other languages). Work on enriching the linguistic thesaurus, on lexical phrases stimulates thought activity. The last component is no less actualized with modern practice in connection with the atrophied thinking and speech of students.

It is these problem areas of students that the teacher decides in his activities, relying on his own pedagogical experience, on a personal thesaurus, and a creative and creative nature.

In the organization and conduct of the educational process, such qualities of socialization of the teacher's personality as:

- sociocultural adaptation - the ability to capture the attention of the student audience, the ability to build information material according to logical schemes,

- professional competence and erudition, rich, dynamic, flexible language,

- communication skills - ability to build a dialogue with the student audience,

- tolerance - the ability to develop in the student audience tolerance for others, ability to hear and engage in dialogue.

In this regard, the higher technical school is aimed at forming a professionally erudite teacher's personality, which has the qualities of professional mobility and efficiency of social response.

In this regard, higher technical school is aimed at the formation of a professionally knowledgeable personality of the teacher, possessing the qualities of professional mobility and efficiency of social response.

Alongside the implementation of the educational process based on the new generation of FSES HE, the teacher participates in the development of the second conceptual direction - "Science" that points out the need to conduct research activities both for the teacher individually and for the teacher and the student in joint projects and research activities.

In this aspect, it is necessary to emphasize the role of international conferences where presentation of research projects, knowledge exchange takes place. To date, the research activity of teachers is assessed by the "Information system for assessing the rating activity of the teacher" (ISRAT).

We shall try to dwell on this aspect in more detail.

The implemented "Information system for assessing the rating activity of the teacher" actually seems to be very effective and allows us to reveal the degree of activity or passivity of the higher education teaching community in general, the publication activity of specific departments, and finally, each individual teacher. Such a rating assessment by all means obliges the pedagogical community to strive for scientific research, experimentation, innovation, stimulating further intellectual growth and development of the teacher both in research and academic directions. Moreover, today the development of research and educational bases is defined as the priority vector of the development of higher technical schools. We believe that the research and academic activity actively carried out by the 
teacher themselves makes them stay current, be competent in topical issues that are raised and discussed on the pages of prestigious journals, at scientific and practical conferences at various levels and within the highest school. It is important to understand that today the teacher excludes the possibility of passive stay in the profession or conducting only pedagogical, or only research activities. Today higher education is going through the process of adaptation in this actualized direction - embedding teachers in a new format of effective activity, that seems to be very promising for the modern higher technical school [17].

Systematic research work reveals good prospects, namely: it allows for further growth and development of the teacher's personality in terms of expanding the research field of activity, enriching the scientific and instrumental (conceptual) framework, coming to understanding, studying, analyzing new research agenda. Moreover, this activity allows one to feel the pulse of modern scientific research, namely: in what direction the research thought is moving, what concepts are being formed, what innovations are being introduced into practical life.

Consequently, the research activity of the teacher is accompanied by scouting, heuristicity in finding new topics, actualized by time, an innovative and personal principle in expanding and enriching the language of presentation, continuous work with the writings of other researchers, a desire to increase publication activity, and sustainable cooperation with publishers. All this is seen as an acquired positive experience, actualized by the modern scientific research life of the higher technical school. In this regard, the assigned Information System for Assessing the Rating Activity of the Teacher (ISRat) appears to be quite viable and promising.

The teacher's joint research activity with the student, which is also aimed at heuristic discoveries, scientific and technical breakthroughs implemented in design practice is seen as an integral part of their research activity [18]. In the organization of this joint research activity, the need is emphasized for the teacher to focus not only on the students' acquisition and formation of a system of knowledge, abilities and skills, but also on the development of their cognitive and creative abilities, the acquisition and expansion of the experience of collective activity and personal responsibility of each participant.

In such activities, social and personal, professional and general cultural competencies acquired by students in scientific and innovative activities are actually strengthened.

In this joint process, the principles of individualization and differentiation of learning are implemented, which imply: the development of individual approaches in order to determine the creative abilities of the student's personality; forecasting the prospects for personal growth and development, humanization and democratization of communication between the teacher and the student; deployment of motivational and volitional qualities (motives, practices, skills, habits); formation of cognitive-axiological functions (logical skills, heuristic skills, value orientations); development of behavioral forms (practical actions and moves); application of knowledge in unusual non-standard situations based on the principle of connection between theory and practice. In such joint research activities, partnership and communication skills - co-creation - are developed. Moreover, on the basis of personal examples of the participants in the scientific process, persuasion skills are formed, the priority of positive stimulation, tolerance to another opinion, the right to make a mistake, the right to one's own choice are revealed.

In this context, a wide field of research and innovation projects, whose presentation takes place during the student's "Science Days", opens up for the student today. Moreover, the students have an opportunity to publish their scientific ideas in different types of journals (VAK, prestigious journals covered in the Scopus and WoS databases) $[19,20]$. In this aspect, we would especially like to dwell on the coverage of the issue of the student's social and personal competencies whose formation and development allows for the process 
of increasing knowledge, capabilities, and practical skills. We note specially that the effective enhancement of such competencies takes place not only in the active teaching and educational process, but also in the research activities of the student. It is this activity that opens up a wide field of opportunities for the student - knowledge, the ability to think creatively, to apply the knowledge gained to practical life. In this regard, the very attitude to the student's personality as to the subject of education becomes relevant and the task of the teaching community is seen in the maximum deployment of their creative abilities, in order to form a creatively oriented personality, capable of finding novelty, non-standard solutions, original manifestation, heurist city. Only such a personality of the student is distinguished by the activity of perception and effort. Due to a very wide range of requirements imposed on the student at the higher technical school today, it is possible to emphasize that they must be involved in research work from the first steps of training at a university, relying on their individual and personal axiomatics of interests. Moreover, we especially note that higher education opens up a wide field for students to implement research projects (through student forums, conferences, intellectual games, as well as opportunities to participate in other very important social projects - the diverse volunteer movement, in particular, actualized by the moment - digital volunteering).

In the process of joint activities of the teacher and the student, an active exchange in the cognitive field is carried out, the significance of the reflective dialogue increases, the quality of training of the student and the teacher's willingness to accept the new challenges of the information society in the context of the transition to the digital economy become more obvious.

Consequently, in the content interpretation of the "Science" direction, the key positions are highlighted that determine the teacher's skill and the quality of the educational process in terms of applying the knowledge gained to research activities.

And, finally, in the implementation of another conceptual direction, "University and Society", the teacher's activity is seen as no less important. This direction has been actualized due to the fact that today the level of demand for its graduates in the labor market plays a key role in the formation of the rating of a particular university. Within the framework of this direction, we saw the opportunity for the teaching staff of developing very promising projects, for example:

- projects related to the introduction of new approaches to the conceptual design of technical education in the framework of the dialogue of higher education with production teams;

- projects aimed at establishing interregional and international cooperation on the organization and development of higher technical education and forms of strengthening the ties with manufacturing;

- projects for the exchange of experience in the employment of graduates.

Today, the implementation of the direction "University and Society" is actualized at the state level due to the need to accumulate higher technical school graduates within the city, region, state, in order to prevent the "washout" of youth $[4,10]$. The loss of intellectual potential is especially felt in all spheres of life. And therefore, the task of retaining young personnel of the engineering and technical corps, involving them in innovative scientific and technical research projects, the development of social infrastructure (new redesigned types of research institutes) for these purposes is seen today as the main task assigned at the federal and solved at the regional levels. Specifically, the university community forges ties with manufacturing in its own way. Employment offers come from the enterprise, a presentation of the enterprise itself is held, workplaces are monitored, and the students have the opportunity to take in the situation, choose an acceptable offer even while studying at the higher school.

The positive factor of this practice is that this problem of "loss" of the younger 
generation is being pondered at all administrative and managerial levels, and specific steps are being taken towards its positive solution. In connection with the state-assigned tasks of accelerating socio-economic growth, achieving economic breakthroughs, the young generation should be directly involved in such innovative activities. And in this field, the administrative and managerial responsibility is important of both the university itself and enterprises that accept young qualified personnel and are ready to provide them with the necessary support and assistance.

Having analyzed the conceptual directions, we would especially like to dwell on the coverage of the issue of professional and universal cultural competencies of the teacher, the formation and development of which allows for the process of building up knowledge, capabilities, and practical skills. We note specially that the effectiveness of the teacher's activities takes place in an active educational process and in research activities and largely depends on the discipline and organization of the teacher themselves.

\section{Conclusions}

Thus, considering higher technical education, we highlight the main thing - it should organically fit into the modernization process, but at the same time it becomes important to implement the conceptual directions "Education", "Science", "University and Society", which at the present stage are largely ensured by the pedagogical corps - experience in teaching, deep professionalism, universal cultural thesaurus and pedagogical creativity. The creation of new technical forms of support (in parallel with the traditional forms and methods of teaching and educating), institutional mechanisms of regulation computerization, informatization and online formats - make it possible to quickly build the educational process. The actively introduced distance forms of interaction at the organizational level also very effectively contribute to the discipline of both the teacher and the students, building an interactive dialogue between the teacher and the student. Research activities are aimed at expanding communication experience, intellectual breakthroughs.

At the present stage, Russian higher technical education as a whole is associated with the development of the teacher's personal characteristics - social and cultural activity, erudition, adaptability - that are significant in terms of their self-realization under conditions of fulfilling the effective contract. In our opinion, the preservation of the historically established principle of organizing the educational process - combining or alternating educational activities with practical participation in social life - is seen as important in modern higher technical education. This is the basis for the purposeful development and transfer of professional and universal cultural competencies of the teacher to the students - enrichment with new knowledge in research work, acquisition of new skills and capabilities in mastering online formats, expanding the field of creative activity.

\section{References}

1. A.V. Belotserkovsky, On the Challenges and Risks to Russian Higher Professional Education, Journal of Higher Education in Russia, 7, 3-9 (2012)

2. E.V. Karavaeva Qualifications of Higher Education and Professional Qualifications: Harmonization with Efforts, Journal of Higher Education in Russia, 12 (218), 5-12, (2017)

3. V.V. Kondratyev Engineering Pedagogy as a Base for Technical Teacher Training System, Journal of Higher Education in Russia, 2 (220), 29-38, (2018)

4. G.M. Romantsev, N.V. Ronzhina, E.F. Zeer and others, Theory and Practice of 
Professional Pedagogical Education, 3, 309 p. (2013)

5. I.E. Uflyand, L.V. Zanina, L.V. Goryunova, The Main Goals and Objectives of the Bologna Process Implementation, p. 56, (2004)

6. A. Maslow, Motivation and Personality: transl. from Engl p. 352, (2003)

7. V.D. Shadrikov, From an Individual to Individuality: An Introduction to Psychology, p. 200 (2009)

8. E.N. Arkhipova, Automation of Rating Evaluation of Teacher's Activities // University Management: Practice and Analysis, 51-62 (2010)

9. I.E. Zadorozhnyuk, S.V. Kireev, University Ranking: Sociological Support, Journal of Higher Education in Russia, 11, 55-65 (2016)

10. I.V. Zakharova, Marketing Tools in Modern Higher Education Institution: Tendencies of Research, Journal of Higher Education in Russia, 27 (6), 20-30, (2018)

11. V.A. Lazarenko, V.A. Lipatov, T.A. Oleynikova, D.A. Severinov, N.B. Filinov, Efficiency of Ranking Implementation in University Management System: Practical Experience, Journal of Higher Education in Russia, 6, 9-19. (2018)

12. I.G. Manoilenko, On the Development of an Information System for Rating Teachers, Journal of Modern Technics and Technologies, 12 (40), 70-79, (2014)

13. M.G. Ganchenkova, I.E. Zadorozhnyuk, V.M. Kalashnik, Scientific and Technological Career in the Research University Journal of Higher Education in Russia, 6, 108-114 (2017)

14. V.M. Prikhod'ko, Z.S. Sazonova, Engineering pedagogy as the base for training of modern engineers and academic staff of technical universities, Journal of Higher Education in Russia, 4, 6-12, (2014)

15. V.S. Senashenko, N.A. Pykhtina, Continuity of Undergraduate and Graduate Programs as a Key Factor of the Quality Assurance in Higher Education, Journal of Higher Education in Russia, 12 (218), 13-25, (2017)

16. N.I. Prokopov, S.N. Antonyuk, S.Yu. Ivanov, D.V. Ivanova Development of University Innovative Potential as a Factor Contributing to the Growth of Labor Satisfaction of Young Teachers, Journal of Higher Education in Russia, 27 (7), 39-44, (2018)

17. M.A. Gorshkov, F.E. Sheregi, Youth of Russia: A Sociological Portrait, 592 p. (2010)

18. P. Kelly, H. Koates, R Naylor, Leading Online Education from Participation to Success, Journal of Educational Studies, 3, 34-58, (2016)

19. E.V. Krekhovets O.V. Poldin, Social Capital of Students in the Light of Social Networks: Structure and Key Actors Analysis, Journal of Educational Studies, 3, 5979, (2016)

20. V.S. Senashenko, On the Correlation Between Professional Standards and Federal Educational Standards of Higher Education, Journal of Higher Education in Russia, 6 , 3-36 (2015) 